\title{
Pobreza, desigualdade e políticas públicas: caracterizando e problematizando a realidade brasileira
}

\author{
Maria Ozanira da Silva e Silva \\ Universidade Federal do Maranhão (UFMA)
}

Pobreza, desigualdade e políticas públicas: caracterizando e problematizando a realidade brasileira Resumo: Este artigo traz reflexões sobre as categorias pobreza, desigualdade e exclusão social como referências teóricas para analisar a política social. Traz com destaque as categorias pobreza e desigualdade para resgatar a implantação e o desenvolvimento das políticas públicas de corte social no Brasil. Para tanto, considera-o quadro social brasileiro e os programas sociais direcionados, historicamente, para o enfrentamento da pobreza no país. Nesse contexto, enfatiza a conjuntura recente com indicação do declínio nos índices de pobreza e desigualdade social e da elevação dos recursos orçamentários para financiamento dos programas sociais, mormente após a Constituição Federal de 1988. Desenvolve uma problematização sobre os programas sociais implementados no Brasil para enfrentamento da pobreza e da desigualdade social, apontando seus limites e a centralidade dos programas de transferência de renda para a proteção social.

Palavras-chave: pobreza, desigualdade social, exclusão social, política social.

Poverty, Inequality and Public Policies: Characterizing and Analyzing the Brazilian Reality

Abstract: This article reflects on the categories of poverty, inequality and social exclusion as theoretical references to analyze social policy. It highlights the issues of poverty and inequality to review the implementation and development of public social policies in Brazil. It analyzes Brazil's social situation and social programs historically aimed at confronting poverty in the country. It emphasizes the recent conjuncture that indicates a decline in rates of poverty and social inequality and increased budget resources for financing social programs, particularly since enactment of the federal Constitution of 1988. It analyzes social programs implemented in Brazil to confront poverty and social inequality, indicating their limits and the importance of income transfer programs for social protection. Key words: poverty, social inequality, social exclusion, social policy. 


\section{Introdução}

Neste texto desenvolvo uma reflexão sobre as categorias pobreza, desigualdade e exclusão social enquanto referências teóricas que têm orientado a formulação e a implementação de políticas públicas de corte social no Brasil. A reflexão leva-me a optar pela pertinência da categoria pobreza, para me referir à realidade socioeconômica da sociedade brasileira. Isso, por considerar a indeterminação e a amplitude do conceito de exclusão social para qualificar as situações de deterioração no campo econômico e da proteção social em países de capitalismo avançado, mormente identificadas e expandidas no contexto da reestruturação capitalista, com prevalência nos anos 1980 e 1990.

Como é considerada neste artigo, a pobreza assume no Brasil uma dimensão abrangente, evidenciando um quadro amplo para intervenção de políticas públicas de corte social, entendendo que as políticas sociais, para serem mais eficazes, devem estar articuladas a políticas macroeconômicas que garantam um crescimento econômico sustentado; a geração de emprego; a elevação da renda proveniente do trabalho e, sobretudo, a redistribuição de renda ainda altamente concentrada no Brasil.

Identifica-se um consenso, tanto no campo acadêmico como entre políticos de todas as matizes ideológicas e partidárias, que a pobreza no Brasil decorre, em grande parte, de um quadro de extrema desigualdade, marcado por profunda concentração de renda. Essa situação coloca o Brasil entre os países de maior concentração de renda no mundo, apesar do declínio nesse índice que se vem registrando, conforme é considerado no presente artigo.

O artigo aborda, a seguir, o conceito de exclusão social e pobreza para referenciar a análise das políticas sociais desenvolvidas para a melhoria do quadro social no Brasil.

\section{Exclusão social e pobreza como referências para as políticas públicas no Brasil}

Parto do entendimento de que o pleno emprego é incompatível com o processo de acumulação gerado nas formações sociais capitalistas. Nesse sentido, a produção de acumulação capitalista, baseada na exploração, é estruturalmente excludente (MARX, 1980). Esse aspecto é demonstrado por Marx em suas análises sobre o processo de produção do capital. Como admite Sposati (1999), a exclusão não é um fenômeno novo. Decorre do processo de acumulação capitalista, apresentando caráter estrutural com agravamentos cíclicos, portanto, é próprio da sociedade capitalista incluir e excluir.

Todavia, coloco a pertinência ou não do conceito de exclusão social para compreensão do quadro so- cial brasileiro. Assim, falar de exclusão social nos remete ao debate europeu, mais especificamente ao debate francês, destacando-se Paugan e Castel. Ambos criticam o conceito de exclusão social por ser portador de indeterminação e consideram a necessidade de recorrência a conceitos como "desfiliação social" e "desqualificação social" para atribuir uma dimensão de processo ao conceito de exclusão social.

O ponto central do debate refere-se à amplitude do conceito de exclusão social, utilizado para designar pessoas e grupos vivenciando as mais diversas situações, desfiliados para Castel e desqualificados para Paugan. Assim, exclusão refere-se a minorias, (negros, homossexuais, pessoas com deficiência), favelados, meninos de rua, catadores de lixo etc. (VÉRAS, 1999, p. 14), escamoteando o caráter processual e dinâmico das situações e sua natureza estrutural e multidimensional.

Paugan (1999), na sua abordagem sobre a exclusão social, considera esse conceito o centro do debate social e político, principalmente na Europa. Destaca o uso variado e impreciso do termo. Ressalta o uso prevalente da categoria "nova pobreza" nos anos 1980, substituída pela categoria exclusão social nos anos 1990, em especial, na França. Essa categoria é utilizada para designar processos que alcançam camadas da população, em razão de mudanças que produzem acúmulo progressivo de dificuldades, decorrentes principalmente do desemprego prolongado e da precarização do trabalho. Trata-se de um processo que desfaz os vínculos sociais, sendo proposto pelo autor o conceito de "desqualificação social" para complementar uma compreensão mais adequada do que vem sendo denominado de exclusão social. $\mathrm{O}$ autor ressalva que o conceito de desqualificação social não pode ser generalizado por referir-se a países desenvolvidos que apresentam forte degradação do mercado de trabalho, considerando que as pessoas já conheceram situações melhores, sentindo-se humilhadas por recorrer à assistência. Assim, a partir de estudos empíricos, Paugan (1999, p. 63) compreende a desqualificação social como o "processo de expulsão do mercado de trabalho e as experiências vividas em relação com a assistência que os acompanham em diferentes fases".

Castel, tratando do que denomina de armadilhas da exclusão, desenvolve críticas sobre o que considera imposição do conceito de exclusão social para definir todas as modalidades de miséria do mundo: o desempregado de longa duração, o jovem da periferia, o sem domicílio fixo etc. (CASTEL, 2000). Assim, o autor propõe uso reservado ou a substituição do conceito de exclusão pelo que denomina de "desfiliação social" para designar o desfecho do processo de transição da integração para a vulnerabilidade. Portanto, não se trata de "zonas" estáti- 
cas, mas de um processo, podendo existir indigência integrada, no caso das populações assistidas. Assim, a dimensão econômica não é o diferenciador essencial, devendo ser considerada em articulação com a proteção social (CASTEL, 1999, p. 25).

Portanto, como vem sendo colocado no debate francês, a exclusão social é uma expressão da realidade dos países desenvolvidos, sobretudo, do final do século 20, com a manifestação de grande elevação do desemprego, agravada pela progressiva precarização do trabalho e pelo afrouxamento da proteção social, que marcaram uma crise da sociedade salarial (CASTEL, 1999), com quebra da cidadania, visto que "não se nasce excluído, não se esteve sempre excluído" (CASTEL, 2000, p. 22).

No Brasil, o que se tem é um grande contingente populacional que sempre esteve à margem da sociedade; que nunca teve inserção no trabalho formal nem participou da sociabilidade ordinária. Não ser incluído é uma condição estrutural que tem marcado gerações após gerações. Falar de exclusão social no Brasil seria admitir uma "perda virtual de uma condição nunca alcançada” (SPOSATI, 1999, p. 133). Temse uma sociedade, no dizer de KOWARICK (1999), extremamente marginalizadora do ponto de vista econômico e social que tem constituído massas de trabalhadores autônomos ou assalariados com rendimentos ínfimos que os levam a uma vida precária e sem proteção social, considerados potencialmente perigosos. De modo que, no Brasil, a pobreza aprofundouse como consequência de um desenvolvimento concentrador da riqueza socialmente produzida e dos espaços territoriais, representados pelos grandes latifúndios no meio rural, e pela especulação imobiliária no meio urbano. Tem raízes na formação sóciohistórica e econômica da sociedade brasileira.

Considerando o limite da categoria exclusão social para compreensão do quadro social brasileiro, proponho a categoria pobreza para proceder a análise das políticas públicas.

A temática da pobreza tem sido objeto de preocupação no campo teórico-conceitual e de intervenção social, verificando-se explicações sobre a emergência, persistência e sua ampliação globalizada. Nesse processo, sua redução ou regulação é considerada necessária para permitir a manutenção do sistema de produção capitalista.

O pressuposto da carência, da escassez de meios de subsistência é recorrentemente utilizado para qualificar a pobreza estrutural e a desvantagem em relação a um padrão ou nível de vida dominante, pobreza relativa (SILVA, 2003, p. 234). Entrentanto, no campo teórico-conceitual sobre a pobreza, identificam-se diferentes concepções que orientam a construção e a implementação de alternativas de políticas públicas.

Entre as concepções explicativas e inspiradoras de políticas de intervenção sobre a pobreza ${ }^{1}$, têm-se as abordagens culturalistas que centralizam sua explicação nos comportamentos e valores dos indivíduos e suas famílias. Orientam-se por valores morais tradicionais que situam o pobre como diferente e portador de uma cultura inferior reprodutora da situação de pobreza dos adultos e de seus descendentes (KATZ, 1989).

É, porém, o paradigma de inspiração liberal, nas suas diferentes variações, o mais recorrente nas explicações e nas orientações de políticas públicas na sociedade capitalista. Nesse campo, o mercado se configura como o espaço natural de satisfação das necessidades econômicas e sociais dos indivíduos, sendo as políticas públicas reduzidas a ações residuais ou marginais, compensatórias, tendo em vista o alívio de situações de pobreza extrema.

Todavia, entendo que as abordagens estruturais, que buscam as explicações da pobreza nas determinações estruturais, constituem campo mais fértil para sua explicação. Considero que categorias como classes sociais, exército industrial de reserva, lumpemproletariado, exploração e desigualdade (SILVA, 2002, p. 79) são profícuas para explicar a pobreza na contemporaneidade. $\mathrm{O}$ entendimento é de que o sistema de produção capitalista, centrado na expropriação e na exploração para garantir a mais valia, e a repartição injusta e desigual da renda nacional entre as classes sociais são responsáveis pela instituição de um processo excludente, gerador e reprodutor da pobreza, entendida enquanto fenômeno estrutural, complexo, de natureza multidimensional, relativo, não podendo ser considerada como mera insuficiência de renda. É também desigualdade na distribuição da riqueza socialmente produzida; é não acesso a serviços básicos; à informação; ao trabalho e a uma renda digna; é não participação social e política. Esse entendimento permite desvelar valores e concepções inspiradoras das políticas públicas de intervenção nas situações de pobreza e as possibilidades de sua redução, superação ou apenas regulação.

\section{Enfrentamento da pobreza no Brasil: políticas públicas de corte social}

Em estudos anteriores sobre as políticas sociais, (SILVA, 2001, 2003, 2005; SILVA et al., 2007), orientome pelo pressuposto de que no desenvolvimento da Política Social brasileira tem-se um conjunto amplo e variado, mas descontínuo e insuficiente, de programas sociais direcionados para segmentos empobrecidos da população. Essas medidas de intervenção não são configuradas como estratégia de caráter global para enfrentamento da pobreza no país (DRAIBE, 1995), embora esse quadro venha se modificando a partir, sobretudo, dos anos 2000. Nesse sentido, a política social no Brasil tem assumido uma perspectiva margi- 
nal e assistencialista, desvinculada das questões macroeconômicas, servindo mais para regulação ou administração da pobreza num dado patamar.

Até os anos 1980, no Brasil, a "cidadania" limitava-se aos trabalhadores inseridos no mercado formal de trabalho, "cidadania regulada" (SANTOS, 1987). Esse quadro começa a ser alterado com a instituição da Seguridade Social, introduzida na Constituição Federal de 1988, em decorrência de lutas sociais pela ampliação e universalização de direitos sociais. Contudo, a crise fiscal do Estado nos anos 1980 e a adoção do Projeto Neoliberal, nos anos 1990 , abriram espaço para programas focalizados na população pobre.

Mesmo com a universalização das atenções primárias de saúde e do ensino fundamental, estas não alcançaram patamar desejável de universalização. A consequência foi a expansão do ensino privado e de planos de saúde contratados principalmente por pessoas da classe média, com recente ampliação entre segmentos de poderes aquisitivos muito baixos.

No campo da alimentação e da nutrição foram registradas algumas medidas, direcionadas principalmente para os trabalhadores do mercado formal, por terem sido assumidas por empresas privadas e públicas que instituíram o cupom alimentação para seus empregados. Nesse campo, pode ser considerado exceção o programa da Merenda Escolar, destinado a crianças que frequentam escolas públicas, importante reforço para a nutrição e a aprendizagem de milhões de crianças pobres (SILVA et al., 2007).

Chegamos aos anos 1990 com uma política de assistência social federal centralizada no então Ministério de Bem-Estar Social, assumida pela Legião Brasileira de Assistência (LBA) e pelo Centro Brasileiro para a Infância e Adolescência (CBIA), extintos em 1995 sob a alegação do vício da máquina administrativa marcada pela corrupção e o clientelismo.

Com a Constituição Federal de 1988 é que começam a se desenvolver, na prática, tendências de descentralização e de municipalização, colocadas na agenda política brasileira pela luta dos movimentos sociais dos anos 1980.

AAssistência Social, política não contributiva, que, juntamente com a Saúde, política que se propõe universal, e a Previdência Social, política contributiva, passam a constituir a Seguridade Social preconizada pela referida Constituição.

No campo das políticas públicas direcionadas ao enfrentamento da pobreza no Brasil, a ampliação do benefício mínimo da Previdência Social para trabalhadores urbanos e rurais para um salário mínimo e a extensão da aposentadoria para os trabalhadores rurais, independentemente de contribuição passada, representam medidas de significativo impacto na vida de amplo contingente da população brasileira. A aposentadoria social rural constitui-se, na atualidade, na principal política de enfrentamento à pobreza no campo, atendendo a 7,8 milhões de trabalhadores rurais, em 2008, dos quais apenas cerca de $10 \%$ contribuíram para a Previdência Social. Ao lado da aposentadoria social rural, merece destaque o Benefício de Prestação Continuada (BPC), criado em 1993, no âmbito da Lei Orgânica de Assistência Social, iniciando-se sua implementação a partir de 1996. Tratase de um benefício de caráter não contributivo, para pessoas idosas a partir de 65 anos de idade e para pessoas com deficiência, incapacitadas para o trabalho. Ambos, idosos e pessoas com deficiência, devem viver em famílias com uma renda per capita familiar de até 1/4 do salário mínimo (em 2010, R \$ 127,50). O público atendido por esse programa, em 2008, foi de 3,4 milhões de pessoas, sendo 1,8 milhão de deficientes e 1,6 milhão de idosos com 65 anos ou mais (IPEA, 2010).

Em relação ao trabalho, cabe destaque ao seguro desemprego com 6,9 milhões de trabalhadores atendidos em 2008 e o abono PIS/PASEP, no mesmo ano, com 8,4 milhões de trabalhadores atendidos com renda de até dois salários mínimos, referente a 2007 (IPEA, 2010).

Nos anos 1990, há que se destacar o Plano de Combate à Fome e a Miséria (PCFM), criado em 1993, pelo Presidente Itamar Franco (1993-1994), direcionado ao enfrentamento da fome, da pobreza e da indigência. Direcionou-se a 32 milhões de indigentes diagnosticados pelo Mapa da Fome, desenvolvido pelo Instituto de Pesquisa Econômica Aplicada (IPEA) ${ }^{2}$.

O PCFM foi interrompido no início do primeiro mandato do governo do presidente Fernando Henrique Cardoso (1995-1998), sendo criado o Programa Comunidade Solidária, a principal estratégia para enfrentamento da pobreza nesse governo. Seria uma nova estratégia para enfrentar a pobreza e a exclusão social, mediante a articulação de ações já desenvolvidas por diferentes Ministérios, numa perspectiva descentralizada e com a participação e parceria da sociedade (SILVA, 2001). Visava incentivar ações em duas frentes: atribuição de um selo de prioridade e gerenciamento de programas de diferentes Ministérios que tivessem maior potencialidade de impacto sobre a pobreza e identificação dos municípios que apresentassem maior concentração de pobreza, onde os programas seriam desenvolvidos.

Percebida a limitada eficácia do Comunidade Solidária no enfrentamento da pobreza no Brasil, foi criado, em julho de 1999, o Programa Comunidade Ativa. A proposta era construir uma agenda local integrada por programas indicados pela comunidade com posterior implementação dos programas agendados, com parceria dos governos federal, estadual e municipal e da comunidade. $\mathrm{O}$ entendimento dos idealizadores dessa proposta era de que, com a indução do desen- 
volvimento local, integrado e sustentável de municípios pobres, seria possível superar o assistencialismo na política de enfrentamento à pobreza.

Dando prosseguimento às medidas de políticas públicas de enfrentamento à pobreza, em junho de 2001, foi criado o Fundo de Combate à Pobreza. Esse Fundo passou a financiar programas de transferência de renda associados à educação e a ações de saneamento, consideradas áreas de maior impacto sobre a pobreza. Os programas de transferência de renda passam a constituir o eixo central da proteção social no país, com ampliação de programas federais, como o Bolsa Escola ${ }^{3}$ e o Bolsa Alimentação ${ }^{4}$.

No mesmo ano foi criado o Programa de Combate à Miséria, conhecido como Índice de Desenvolvimento Humano (IDH-14), que, posteriormente, passou a ser chamado de Projeto Alvorada. Esse foi um programa direcionado, prioritariamente, aos bolsões de miséria das Regiões Norte e Nordeste, as regiões mais pobres do país, depois estendido para outros estados com municípios de IDH inferior a 0,500 (SILVA et al., 2007).

A partir de 2001, o governo de Fernando Henrique Cardoso, que vinha dando pouca atenção a ações de políticas sociais, priorizando o ajustamento da economia brasileira para inserção do país na economia globalizada, numa clara opção pelo projeto neoliberal, passou a se interessar pela organização de uma "Rede de Proteção Social" formada por 12 programas, todos situados no campo da transferência de renda para famílias ou indivíduos (SILVA, YAZBEK; GIOVANNI, 2008).

Nesse processo de construção de políticas públicas para enfrentamento da pobreza no Brasil, o ano de 2003, quando se iniciou seu primeiro mandato, o presidente Luiz Inácio Lula da Silva (2003-2006), no discurso de posse, comprometeu-se a enfrentar a fome e a pobreza no país. Para isso, anunciou como principal estratégia o Fome Zero ${ }^{5}$. No âmbito dessa estratégia, os programas de transferência de renda assumem cada vez mais a centralidade para o enfrentamento da pobreza, sendo criado o Bolsa Família, em 2003.

O Bolsa Família é o maior programa de transferência de renda em implementação no Brasil, com implementação descentralizada em todos os municípios.

Propõe-se a proteger o grupo familiar, com atendimento de famílias extremamente pobres, com renda per capita mensal de até $\mathrm{R} \$ 70$ com qualquer composição, e famílias pobres, com renda per capita mensal entre $\mathrm{R} \$ 70$ a R \$ 140 desde que tenham gestantes, nutrizes, ou crianças e adolescentes entre 0 a 17 anos. As famílias extremamente pobres recebem um benefício básico de $\mathrm{R} \$ 68$ podendo receber um benefício variável de mais $\mathrm{R} \$ 22$ por cada filho de até 15 anos de idade, até três filhos. As famílias pobres recebem uma transferência monetária variável de até $R$ \$ 66 ou seja, $R$ \$ 22 mensais por cada filho de até 15 anos de idade, considerando no máximo três filhos. ${ }^{6}$ As famílias pobres e extremamente pobres, com adolescentes de 16 e 17 anos, recebem um adicional de $\mathrm{R} \$ 33$ por até dois adolescentes, desde que continuem frequentando a escola. As famílias têm liberdade na aplicação do dinheiro recebido e podem permanecer no Programa, enquanto houver a manutenção dos critérios de elegibilidade e forem cumpridas as condicionalidades de manutenção de crianças e adolescentes de 7 a 15 anos na escola; frequência regular de crianças de 0 a 6 anos aos postos de saúde e realização do pré-natal pelas mulheres gestantes.

O Bolsa Família propõe articular a transferência monetária a ações complementares mediante articulação com outros programas de natureza estruturante, com destaque para a educação, saúde e trabalho. Segundo informações acessadas no site do MDS (www.mds.gov.br), em 09/06/2010 eram atendidas 12.548.861 famílias pobres ou extremamente pobres com renda per capita familiar de até $\mathrm{R} \$ 120$. O orçamento do Bolsa Família em 2009 foi de R\$ 10,9 bilhões, sendo previsto para 2010 um orçamento de $\mathrm{R} \$ 12$ bilhões, o que representa um crescimento de $10 \%$ sobre o orçamento de 2009.

Muitos estudos têm procurado dimensionar o impacto do Bolsa Família, evidenciando uma significativa e contínua diminuição da pobreza e da desigualdade no país desde 2001. Barros et al. (2007a) apontam que o Índice de Gini, uma das medidas da desigualdade mais usadas no mundo, registrou declínio de 4,6\% no Brasil, passando de 0.594 em 2001 para 0.566 em 2005. Esse foi o maior declínio da desigualdade nos últimos 30 anos. Barros et al. (2007b), em outro estudo, identificaram que de 2001 a 2005 a renda anual no Brasil apresentou um discreto crescimento de $0,9 \%$, mas beneficiou sobretudo a população pobre. No mesmo período, o índice de crescimento da renda dos $10 \%$ e dos $20 \%$ mais ricos da população foi negativo $(-0,3 \%$ e $-0,1 \%$, respectivamente), enquanto o crescimento da renda dos $10 \%$ mais pobres foi de $8 \%$ ao ano. Esse aspecto contribuiu para o declínio do Índice de Gini em 4,6\% de 2001 para 2005. É importante considerar que, pela primeira vez no Brasil, a pobreza foi reduzida em decorrência, sobretudo, da redução da desigualdade, permitindo que os índices de pobreza e de extrema pobreza diminuíssem $4,5 \%$, cada um, naquele período.

A Pesquisa Nacional por Amostra de Domicílios (PNAD) 2006 (IBGE, 2007) identificou que o Índice de Gini caiu de 0,547 em 2004 para 0,543 em 2005 e 0,540 em 2006, registrando em 2007, 0,528. Todavia, apesar desse declínio, a renda do trabalho continuou muito concentrada. Em 2006, os $10 \%$ da população inserida no mercado de trabalho, de renda mais baixa, detinham somente $1 \%$ do total da renda. Ao mes- 
mo tempo, os $10 \%$ dos trabalhadores com renda mais alta detinham $44,4 \%$ da renda total do trabalho. Isso significa que, mesmo com declínio nos índices de desigualdade e pobreza, o Brasil ainda se situa numa posição internacional negativa, abaixo dos $5 \%$ mais desiguais num ranking de 74 países, sendo preciso mais 20 anos para alcançar posição similar se comparado à média dos países com maior ou menor nível de desigualdade (BARROS et al., 2007a).

Considerando a PNAD 2007 (IBGE, 2008), os indicadores do trabalho no Brasil indicavam que a distribuição percentual por classe de rendimento mensal familiar per capita nos arranjos familiares dos domicílios particulares, em salário mínimo, teve o seguinte comportamento: $23,5 \%$ ganhavam até meio salário mínimo; $27,0 \%$, mais de meio a um salário mínimo; 24,3\%, mais de um a dois salários mínimos; $8,2 \%$, mais de dois a três salários mínimos; $6,2 \%$ mais de três a cinco salários mínimos e 5,5\% mais de cinco salários mínimos. Esses dados demonstram a disparidade da distribuição do rendimento mensal familiar per capita nos arranjos familiares residentes em domicílios particulares, se considerados os dois extremos. Nos rendimentos de até um salário mínimo, tem-se a metade dos arranjos familiares $(50,5 \%)$. A situação relativa se mantém em relação à distribuição do rendimento mensal familiar per capita nos arranjos familiares residentes em domicílios particulares de mais de cinco salários mínimos $(5,5 \%)$.

A situação acima reafirma-se quando é considerada a distribuição por classe de rendimento médio mensal familiar per capita em salários mínimos: até meio salário mínimo, 30\%; mais de meio a um salário mínimo, 27\%; mais de um a dois salários mínimos, 22\%; mais de dois a três salários mínimos, 7,1\%; mais de três a cinco salários mínimos, 5,2\% e mais de cinco salários mínimos, 4,1\%. Esses dados demonstram que, mesmo em declínio, a situação de pobreza continuava elevada, apesar de se verificar que os rendimentos dos indivíduos e das famílias vinham acumulando ganhos reais desde 2005 e o salário mínimo vinha sendo reajustado em patamares superiores à inflação.

Convém ressaltar que são apontadas como causas dos declínios da desigualdade e da pobreza no Brasil nos anos recentes: a contribuição dos programas de transferência de renda; o crescimento real do salário mínimo, a estabilidade da economia e os benefícios da previdência social (BARROS et al., 2006; SOARES; RIBAS; OSÓRIO, 2007).

Estudo desenvolvido pelo IPEA em 2008 (IPEA, 2008) sobre a pobreza e a riqueza nas seis maiores metrópoles urbanas no Brasil $^{7}$ reafirma a tendência antes indicada, demonstrando que o crescimento produtivo do país foi acompanhado, no período 2003 a 2007, pela melhoria da renda de todas as famílias, com diminuição do número de pobres, tendência mantida em 2008. O número de pobres caiu de 35,0\% em 2003 para 24,1\%, em 2008. Foi ainda mais significativa no período a diminuição do número de indigentes, de $48,3 \%$ para $43,8 \%$ de 2003 a 2008 . O estudo aponta como causas para redução da pobreza e da indigência o crescimento econômico, ganho real do salário mínimo e o dinheiro transferido do governo para os pobres.

Em outro estudo também realizado pelo IPEA, nas mesmas seis metrópoles, sobre desigualdade e pobreza metropolitana durante a crise internacional (IPEA, 2009), verificou-se que o Índice de Gini, entre janeiro $(0,514)$ a junho de $2009(0,493)$ caiu 4,1\% . Em relação à pobreza, o estudo demonstrou que, no período de março de 2002 (42,5\%) a junho de 2009 $(31,1 \%)$, a taxa de pobreza do Brasil metropolitano caiu $26,8 \%$. O estudo sustenta que a transferência monetária do governo aos pobres pode ter contribuído para essa realidade.

Complementando a análise acima, a pesquisa realizada pelo IPEA (IPEA, 2010) ${ }^{8}$ sobre pobreza, desigualdade de renda e políticas públicas no mundo e no Brasil nos anos recentes aponta como causas da diminuição consistente da pobreza e da desigualdade, uma combinação de fatores: continuidade da estabilidade monetária, a maior expansão econômica e o reforço das políticas públicas, com destaque à elevação real do salário mínimo, a ampliação do crédito popular, reformulação e alargamento dos programas de transferência de renda aos extratos de menor rendimento.

$\mathrm{O}$ estudo considera que o Brasil se destaca no cenário mundial, apesar de não ser um país que tenha registrado o mais rápido decréscimo das taxas de pobreza e de desigualdade de renda até 2005, por vir conseguindo diminuir, ao mesmo tempo, ambas as taxas, observando-se maior redução da pobreza do que da desigualdade. Assim, mantida a tendência, o Brasil pode superar a pobreza absoluta; reduzir para $4 \%$ a taxa nacional de pobreza e o Índice de Geni poderá ficar em 0,488, até 2016, colocando o Brasil no patamar dos países desenvolvidos (IPEA, 2010).

$\mathrm{O}$ estudo mencionado sustenta a realidade indicada mediante os seguintes dados: entre $1995 \mathrm{e}$ 2008, a queda média anual da taxa nacional de pobreza absoluta (até meio salário mínimo per capita) foi $-0,8 \%$ a. a., sendo que no período mais recente de $2003 / 2008$, a taxa anual foi de $-3,1 \%$. A taxa nacional de pobreza extrema (até $1 / 4$ do salário mínimo per capita) foi de $-2,1 \%$ a. a. Essa situação se registrou após a aprovação da Constituição Federal de 2008 que permitiu a elevação do gasto social em relação ao PIB, de 13,3\% em 1985, para $21,9 \%$ em 2005, com destaque à elevação da participação dos municípios de $10,6 \%$ para $16,3 \%$, resultante do movimento de descentralização da política social e da participação social na formulação e gestão das políticas sociais brasileiras. Todavia, o 
mesmo estudo aponta alguns aspectos que devem ser considerados para permitir as perspectivas socioeconômicas brasileiras positivas, tais como: sustentabilidade de uma taxa elevada de crescimento econômico e de baixainflação com orientação do crescimento para produção de bens e serviços, com maior valor agregado e de elevado e avançado conteúdo tecnológico; alteração do padrão tributário extremamente regressivo, onerando mais a base da pirâmide social; alteração no uso do fundo público; incremento de infraestrutura adequada em todo o país e elevação da eficácia na utilização dos recursos públicos. Ademais, o estudo destaca as deficiências relacionadas à coordenação, integração e articulação matricial no conjunto das políticas públicas, em termos horizontais ainda identificadas no Brasil.

O estudo destaca nas suas considerações finais a necessidade de consolidar institucionalmente o quadro geral das leis sociais no Brasil, para elevar o padrão e qualificar a intervenção do Estado no campo social, de modo a regular a responsabilidade e o compromisso social com metas, recursos, cronograma e coordenação de programas.

\section{Conclusão}

A análise do quadro social brasileiro evidencia significativa persistência da pobreza e da desigualdade social, com diminuição nesses índices, com medidas adotadas a partir da Constituição brasileira de 1988. Tem-se nos últimos anos a possibilidade de superação da indigência, embora a pobreza, mesmo que diminuindo de modo mais significativo do que a desigualdade social, pareça vir sendo apenas administrada e controlada.

O desafio é a manutenção de níveis significativos e sustentáveis de crescimento econômico; o controle da inflação; o desenvolvimento de serviços de infraestrutura básica com oferta de serviços básicos de modo ampliado e democrático para toda a população brasileira. Os gastos sociais, mesmo se ampliando, precisam chegar melhor aos mais necessitados, e as políticas sociais carecem de maior articulação entre si e com a política macroeconômica de geração de emprego e de distribuição da renda socialmente produzida.
Uma análise das políticas sociais no Brasil revela, em primeiro plano, a adoção de programas fragmentados, descontínuos e insuficientes para produzir impactos significativos no quadro apresentado. Ademais, têm-se ciclos de crescimento econômico curtos e interrompidos. Nesse percurso, merecem relevância quatro programas: o de Merenda Escolar direcionado às crianças e aos adolescentes que frequentam escola pública no Brasil; a Aposentadoria Social Rural direcionada a trabalhadores do meio rural; o Benefício de Prestação Continuada para pessoas idosas a partir de 65 anos e pessoas com deficiência e o Bolsa Família. Os três últimos são programas de transferência de renda que vêm assumindo a centralidade da proteção social no Brasil. Esses programas situam-se no campo da Política de Assistência Social por independerem de contribuição prévia ou de contribuição sistemática, como o Aposentadoria Social Rural, e por se destinarem a populações pobres, que deles necessitam.

Todavia, uma análise mais profunda dos programas ditos de enfrentamento à pobreza, adotados no Brasil, situa esses programas no âmbito do que Castel (1999) denomina de "políticas de inserção", que limitam sua atuação sobre os efeitos do disfuncionamento social, sem considerar as determinações estruturais, geradoras de pobreza. Tem sido pouco implementadas as "políticas de integração", ou seja, aquelas capazes de produzir grandes equilíbrios de caráter preventivo e não só reparador. Temos tido a proliferação de políticas de inclusão precárias e marginais, orientadas pela focalização na população pobre ou extremamente pobre, incapazes de alcançar as determinações mais gerais e estruturais da situação de pobreza no país. São políticas e programas que têm, até, incluído pessoas nos processos econômicos de produção e de consumo. Contudo, é uma integração da pobreza e da indigência de modo marginal e precário, criando um segmento de indigentes ou de pobres "integrados", mantidos na situação de mera reprodução. Pode-se ter, por conseguinte, uma pobreza regulada ou controlada, mas não superada, servindo para atenuar o caráter "perigoso" que é atribuído aos pobres e permitindo o funcionamento da ordem com o controle social das políticas sociais (SILVA, 2008, p. 149). Dessa forma, a pobreza, ao ser considerada tão somente carência de renda, vem 
sendo reduzida, mantendo-se, porém, inalterada a grande concentração de propriedade que sempre marcou a sociedade brasileira.

\section{Referências}

BARROS, R. P. de, et al. Uma análise das principais causas da queda recente na desigualdade de renda brasileira. Rio de Janeiro: IPEA, 2006. Texto para Discussão, n. 1.258. Disponível em:< www.ipea.gov.br>. Acesso em: nov. 2009.

- A queda recente da desigualdade no Brasil. Rio de Janeiro: IPEA, 2007a. Texto para Discussão, n. 1.258. Disponível em:<www.ipea.gov.br>. Acesso em: nov. 2009.

A importância da queda recente da desigualdade na redução da pobreza. Rio de Janeiro: IPEA, 2007b (Texto para Discussão, n. 1.256). Disponível em: <www.ipea.gov.br>. Acesso em: nov. 2009.

CASTEL, R. As Metamorfoses da questão social. Uma crônica do salário. Petrópolis: Vozes, 1999.

As Armadilhas da Exclusão. In: CASTEL, R; WANDERLEY, L. E. W.; WANDERLEY, M. B. Desigualdade e questão social. São Paulo: EDUC, 2000, p. 17-50.

DRAIBE, S. M. et al. Políticas sociales y programas de combate a la pobreza en Brasil. In: REDE DE CENTROS DE INVESTIGACIÓNACONÔMICAAPLICADA. Estratégias para combater la pobreza em América Latina: programas, instituiciones y recursos. Santiago: Banco Mundial de Desarrollo,1995, p. 97-162.

IBGE-Instituto Brasileiro de Geografia e Estatística. Pesquisa Nacional por Amostra de Domicílios (PNAD 2006). Rio de Janeiro: IBGE, 2007.

. Pesquisa Nacional por Amostra de Domicílios (PNAD, 2007). Rio de Janeiro: IBGE, 2008.

IPEA-Instituto de Pesquisa Econômica Aplicada. Pobreza e riqueza no Brasil metropolitano. Brasília: Comunicação da Presidência, n. 7, ago. 2008.

- Desigualdade e pobreza no Brasil metropolitano durante a crise internacional: primeiros resultados. Brasília: Comunicação da Presidência, n. 25, ago. 2009.

Pobreza, desigualdade e políticas públicas. Brasília: Comunicação da Presidência, n. 38, jan. 2010.

KATZ, M. B. The Undersrving Poor. From War on Poverty to the War on Welfare. New York: Pantheon Books, 1989.
KOWARICK, L. O Conceito de exclusão social. In: VÉRAS, M. P. B.; SPOSATI, A.; KOWARICK, L. (Ed.). O debate com Serge Paugan. Por uma sociologia da exclusão social. São Paulo: EDUC, 1999, p. 138-142.

MARX, K. O capital. Livro 1: O processo de produção do capital. Rio de Janeiro: Civilização Brasileira, 1980.

PAUGAN, S. Abordagem sociológica da exclusão. In: VÉRAS, M. P. B.; SPOSATI, A.; KOWARICK, L. (Ed.). $O$ debate com Serge Paugan. Por uma sociologia da exclusão social. São Paulo: EDUC, 1999, p. 50-62.

SANTOS, W. G. Cidadania e justiça. A política social na ordem brasileira. Rio de Janeiro: Campus, 1987.

SILVA, M. O. da S. (Coord.) O Comunidade Solidária: o não-enfrentamento da pobreza no Brasil. São Paulo: Cortez, 2001.

O debate sobre a pobreza: questões teóricoconceituais. Revista de Políticas Públicas, v. 6, n. 2, p. 65$102,2002$.

. A política pública de transferência de renda enquanto estratégia de enfrentamento à pobreza no Brasil. Revista de Políticas Públicas, v.7, n. 2, p. 233-253, 2003.

Os programas de transferência de renda e a Pobreza no Brasil: superação ou regulação? Revista de Políticas Públicas, v. 9, n. 1, p. 251-278, 2005.

et al. Pobreza no Brasil e na Argentina: dimensão e políticas de enfrentamento. Revista de Políticas Públicas, v. 11, n. 2, p. 171-196, 2007.

. O Bolsa Família no enfrentamento à pobreza no Maranhão e Piauí. São Paulo: Cortez, 2008.

. YAZBEK, M. C.; GIOVANNI, G. Di. A política social brasileira no século XXI: a prevalência dos programas de transferência de renda. São Paulo: Cortez, 2008.

SOARES, F. V.; RIBAS, R. P.; OSÓRIO, R. G. Avaliando o impacto do Programa Bolsa Família: uma comparação com programas de transferência condicionada de renda de outros países. Brasília: MDS, 2007.

SPOSATI, A. Exclusão social abaixo da linha do Equador. In: VÉRAS, M. P. B.; SPOSATI, A.; KOWARICK, L. (Ed.). $O$ debate com Serge Paugan. Por uma sociologia da exclusão social. São Paulo: EDUC, 1999, p. 126-138.

VÉRAS, M. P. B. Notas ainda preliminares sobre exclusão social, um problema brasileiro de 500 anos. In: SPOSATI, A.; KOWARICK, L. (Ed.). O debate com Serge 
Paugan. Por uma sociologia da exclusão social. São Paulo: EDUC, 1999, p. 13-48.

\section{Notas}

1 Um estudo da literatura sobre a pobreza, destacando as questões teórico-conceituais, encontra-se em Silva, 2002.

2 Considerava-se indigente a população que detinha uma renda mensal de até um $1 / 4$ do salário mínimo, suficiente somente para a compra de uma cesta básica de alimento.

3 OPrograma Nacional de RendaMínima VinculadoàEducação - Bolsa Escola foi instituído em 2001 pelo Ministério da Educação. Destinava-se a famílias com crianças de 7 a 15 anos de idade, sendo o benefício transferido para cada família no valor de $\mathrm{R} \$ 15$ por criança, até o máximo de três filhos, totalizando até $\mathrm{R} \$ 45$. A contrapartida eram a matrícula e a frequência da criançaà escola.A partir de 2003, esse programa foi incorporado ao Bolsa Família (SILVA et al. 2007).

4 OBolsaAlimentação, também criadoem 2001, pelo Ministério da Saúde, visava reduzir deficiências nutricionais e a mortalidade infantil entre as famílias com renda per capita de até meio salário mínimo. Destinado a famílias com mulheres gestantes ou que estivessem amamentando os filhos, ou ainda com crianças de 6 meses a 6 anos de idade. Obenefício era de até três Bolsas Alimentação para cada família, ou seja; o valor de $\mathrm{R} \$ 15$ até $\mathrm{R} \$ 45$ por mês. Além da transferência monetária, era oferecido atendimento básico à saúde dafamília. A partir de 2003, esse programa foi também incorporado ao BolsaFamília(SILVAetal. 2007).

5 A estratégia Fome Zero é representada por um conjunto de políticas governamentais e não governamentais cujo propósito maior é erradicar a fome e a desnutrição no país. Seus principais programas são: Bolsa Família; Programa de Aquisição de Alimentos da Agricultura Familiar (PAA); Programa Nacional deAlimentaçãoEscolar(PNAE); Programa de Construção de Cisternas; Programa Nacional de Fortalecimento daAgriculturaFamiliar(Pronaf); Restaurantes Populares e Centros de Referência de Assistência Social (CRAS).

6 O BF ampliou seu público alvo, incluindo também o atendimento de famílias sem filhos, como o caso dos quilombolas, famílias indígenas e moradores de rua.

7 As seis regiões metropolitanas consideradas foram: Recife, Salvador, São Paulo, Porto Alegre, Belo Horizonte e Rio de Janeiro.

8 A pesquisa tem como principais fontes de dados, para as informações internacionais: Nações Unidas (Banco Mundial e World Income Inequality Databas - WILD) e nacionais, a Pesquisa Nacional por Amostra de Domicílios do IBGE e dados dos Ministérios do Planejamento, Orçamento e Gestão (Sigplan)e daFazenda(Siafi).

\section{Maria Ozanira da Silva e Silva}

maria.ozanira@gmail.com

Pós-Doutorado na Universidade Estadual de Campinas (Unicamp)

Doutora em Serviço Social pela Pontifícia Universidade Católica de São Paulo (PUC/SP)

Coordenadora e professora do Programa de PósGraduação em Políticas Públicas da Universidade Federal do Maranhão (PGPP-UFMA)

Coordenadora do Grupo de Avaliação e Estudo da Pobreza e de Políticas Direcionadas à Pobreza (Gaepp: <www.gaepp.ufma.br>)

\section{PGPP - UFMA}

Campus Universitário do Bacanga

Av. dos Portugueses, S/N

São Luís - Maranhão

CEP: 65085-580 